\section{Isolation and Characterization of 7-Hydroxy- 6-demethyl-6-deoxy-erythromycin D, a New Erythromycin Analogue, from Engineered Saccharopolyspora erythraea}

\author{
Courtney M. Starks, Eduardo Rodriguez, \\ John R. Carney, Ruchir P. Desai, Chris Carreras, \\ Robert MCDANiEL, Richard HutCHINSON, \\ Jorge L. Galazzo and PeTER J. LiCARI* \\ Kosan Biosciences, Inc., \\ 3832 Bay Center Place, Hayward, California 94545
}

(Received for publication October 21, 2003)

Erythromycin biosynthesis is mediated by a modular polyketide synthase (PKS). ${ }^{1,2)}$ Such PKSs feature a separate enzyme active site, as part of discrete protein domains for each biosynthetic step catalyzed, making them ideal targets for directed biosynthesis. Alteration or replacement of individual domains or modules has allowed many new polyketides to be generated with modifications at positions not readily accessible by synthetic organic chemistry. ${ }^{3,4)}$

As a starting material for the synthesis of new erythromycin analogues, we set out to generate 6-demethylerythromycins by directed biosynthesis. The 6-methyl group of erythromycin is derived from incorporation of a methylmalonyl unit by the acyltransferase in module 4 (AT4) of the 6-deoxyerythronolide B synthase (DEBS) PKS. ${ }^{5)}$ Recently, REEVES and co-workers ${ }^{6)}$ successfully altered the substrate specificity of AT4 in DEBS through site-specific mutagenesis to accept malonyl-CoA or methylmalonyl-CoA. The modified DEBS genes were expressed in the heterologous host Streptomyces lividans, and consequently, the aglycone 6-demethyl-6deoxyerythronolide $\mathrm{B}$ was produced. RoDRIGUEZ et al. ${ }^{7)}$ described a novel gene delivery and expression system that allows the rapid engineering of recombinant PKSs in an erythromycin overproducing strain of Saccharopolyspora erythraea K24-1. Here, we report the use of that gene delivery system to introduce the DEBS genes harboring a mutagenized AT4 domain into $S$. erythraea K24-1 to produce 6-demethyl erythromycins. Compound 1 (7-hydroxy-6-demethyl-6-deoxy erythromycin D) was produced, which is demethylated at the 6-position as predicted, but unexpectedly has a hydroxyl group at the 7-position rather than at the 6-position.

In order to express the AT4-modified DEBS in $S$. erythraea K24-1, the genes encoding the engineered PKS (mutation 3 in reference 6) were transferred from the $S$. lividans expression vector to the pSET152 integrating vector under control of the native eryAp promoter. ${ }^{7)}$ The resulting vector pKOS159-42 was introduced into $S$. erythraea K24-1 by conjugation and the culture broths of the antibiotic-producing isolates were screened by LC/MS for the presence of compounds with mass spectra consistent with 6-demethyl-erythromycin analogues. One isolate was selected for scale-up in 10-liter bioreactors, which produced high levels of a compound with $\mathrm{m} / \mathrm{z} 690$ consistent with the mass of 6-demethyl-erythromycin D.

Each production bioreactor containing 9 liters of production medium was inoculated with $500 \mathrm{ml}$ of an actively growing culture of $S$. erythrea K24-1::pKOS15942. The bioreactors were operated at $34^{\circ} \mathrm{C}, \mathrm{pH} 7.0 \pm 0.15$, 3 liters per minute (LPM) airflow, and $600 \mathrm{rpm}$ agitation. The dissolved oxygen was maintained above $40 \%$ of air saturation. A dextrin suspension ( $150 \mathrm{~g} / \mathrm{liter})$ was fed at a rate of $5.4 \mathrm{ml} /$ hour throughout the cultivation. The culture broth's $\mathrm{pH}$ was adjusted to 8 before harvesting by centrifugation on day 6 after inoculation.

The centrifuged broth from two 10-liter bioreactors was passed over a solid-phase extraction column and eluted with methanol. LC/MS analysis of the eluate indicated at least three compounds which produced prominent ions of $m / z$ 690. Two of these compounds were present in quantities too low for isolation; the remaining compound (1) was isolated through a combination of solid-phase extraction, liquid-liquid extraction, and reversed-phase column chromatography.

Compound 1 has a molecular formula of $\mathrm{C}_{35} \mathrm{H}_{63} \mathrm{NO}_{12}$, as determined by the ${ }^{13} \mathrm{C}$ NMR spectrum and high-resolution mass spectral data. Carbon-hydrogen connectivities were established from the multiplicity-edited HSQC spectrum, while gsCOSY and constant time HMBC data allowed tracing of the carbon-oxygen skeleton. The NMR data were consistent with a structure similar to the expected 6demethyl-erythromycin $\mathrm{D}$, but having a hydroxyl group at the 7-position rather than the 6-position. In particular, the COSY spectrum indicated coupling between $\mathrm{H}-8(\delta$ 2.51) and H-7 ( $\delta$ 4.41), between H-7 and H-6a ( $\delta$ 2.13), and between H-6a and H-5 ( $\delta$ 3.78). Further evidence for the placement of a hydroxyl group at position 7 , rather than at position 6, came from $\mathrm{HMBC}$ correlations from $\mathrm{H}-7$ to the

\footnotetext{
* Corresponding author: licari@kosan.com
} 
Table 1. The ${ }^{13} \mathrm{C}$ and ${ }^{1} \mathrm{H}$ NMR data for $\mathbf{1}\left(\mathrm{CDCl}_{3}\right)$.

\begin{tabular}{|c|c|c|}
\hline position & ${ }^{13} \mathbf{C}$ & ${ }^{1} \mathbf{H}$ \\
\hline 1 & 178.1 & -- \\
\hline 2 & 45.0 & $2.99, \mathrm{~m}$ \\
\hline 3 & 82.7 & 3.70 , overlap \\
\hline 4 & 41.0 & 1.90 , overlap \\
\hline 5 & 80.2 & 3.78 , overlap \\
\hline 6 & 37.7 & $\begin{array}{l}2.13 \text {, overlap } \\
1.86 \text {, overlap }\end{array}$ \\
\hline 7 & 66.8 & 4.41, br d, $J=8.0 \mathrm{~Hz}$ \\
\hline 8 & 50.0 & 2.51, br q, $J=6.5 \mathrm{~Hz}$ \\
\hline 9 & 211.2 & -- \\
\hline 10 & 43.8 & $2.83, \mathrm{q}, J=7.0 \mathrm{~Hz}$ \\
\hline 11 & 71.1 & 3.72 , overlap \\
\hline 12 & 41.0 & $1.72, \mathrm{~m}$ \\
\hline 13 & 77.4 & $5.05, \mathrm{dd}, J=9.5,4.5 \mathrm{~Hz}$ \\
\hline 14 & 25.3 & $\begin{array}{l}\text { 1.82, overlap } \\
1.51, \text { dqd, } 14.0,7.5,4.5\end{array}$ \\
\hline 15 & 10.6 & $0.92, \mathrm{t}, J=7.5 \mathrm{~Hz}, 3 \mathrm{H}$ \\
\hline 2-Me & 15.2 & $1.22, \mathrm{~d}, J=7.5 \mathrm{~Hz}, 3 \mathrm{H}$ \\
\hline 4-Me & 10.3 & $1.20, \mathrm{~d}, J=7.0 \mathrm{~Hz}, 3 \mathrm{H}$ \\
\hline 8-Me & 7.2 & $1.10, \mathrm{~d}, J=6.5 \mathrm{~Hz}, 3 \mathrm{H}$ \\
\hline $10-\mathrm{Me}$ & 6.3 & $1.04, \mathrm{~d}, J=7.0 \mathrm{~Hz}, 3 \mathrm{H}$ \\
\hline 12-Me & 9.2 & $0.89, \mathrm{~d}, J=7.0 \mathrm{~Hz}, 3 \mathrm{H}$ \\
\hline 1 ' & 105.7 & $4.29, \mathrm{~d}, J=7.5 \mathrm{~Hz}$ \\
\hline $2^{\prime}$ & 70.2 & $3.23, \mathrm{dd}, J=10.0,7.0 \mathrm{~Hz}$ \\
\hline 3 ' & 65.4 & $2.45, \mathrm{~m}$ \\
\hline $\mathrm{N}-\mathrm{Me}$ & 40.2 & $2.25, \mathrm{~s}, 6 \mathrm{H}$ \\
\hline $4 '$ & 28.1 & $\begin{array}{l}1.67, \text { ddd, } J=12.5,3.5,2.5 \mathrm{~Hz} \\
1.20 \text {, overlap }\end{array}$ \\
\hline 5 & 70.4 & $3.59, \mathrm{~m}$ \\
\hline $5^{\prime}-\mathrm{Me}$ & 21.0 & $1.24, \mathrm{~d}, J=6.0 \mathrm{~Hz}, 3 \mathrm{H}$ \\
\hline $1 "$ & 100.4 & $4.94, \mathrm{~d}, J=3.5 \mathrm{~Hz}$ \\
\hline $2 "$ & 40.6 & $\begin{array}{l}2.16, \mathrm{~d}, J=14.0 \mathrm{~Hz} \\
1.82, \text { overlap }\end{array}$ \\
\hline 3" & 69.5 & -- \\
\hline 4" & 76.2 & 2.99 , overlap \\
\hline $5 "$ & 66.5 & 3.77 , overlap \\
\hline 3"-Me & 25.4 & $1.25, \mathrm{~s}, 3 \mathrm{H}$ \\
\hline 5"-Me & 17.7 & $1.31, \mathrm{~d}, J=6.0 \mathrm{~Hz}, 3 \mathrm{H}$ \\
\hline
\end{tabular}

C-8 methyl carbon $(\delta$ 7.23), and from the C-8 methyl protons to $\mathrm{C}-7$ ( $\delta$ 66.77), C-8 ( $\delta 50.0)$, and C-9 ( $\delta$ 211.2). Complete ${ }^{1} \mathrm{H}$ and ${ }^{13} \mathrm{C}$ NMR assignments are listed in Table 1. The one- and two-dimensional NMR data for the rest of the molecule are consistent with the structure shown.

The antibacterial activity of compound 1, tested on Streptococcus pneumoniae, Staphylococcus aureus, Staphylococcus epidermis, Enterococcus faecalis, and Haemophilus influenzae (Table 2), was marginal against microorganisms that are sensitive to erythromycin $\mathrm{A}$. This is not surprising since 1 lacks the $12-\mathrm{OH}$ and the $3^{\prime}-\mathrm{O}-\mathrm{CH}_{3}$ that contribute substantially to antibiotic activity.

The hydroxylation of 6-deoxyerythronolide $\mathrm{B}$ to
Fig. 1. Structure of 7-hydroxy-6-demethyl-6deoxy erythromycin D.

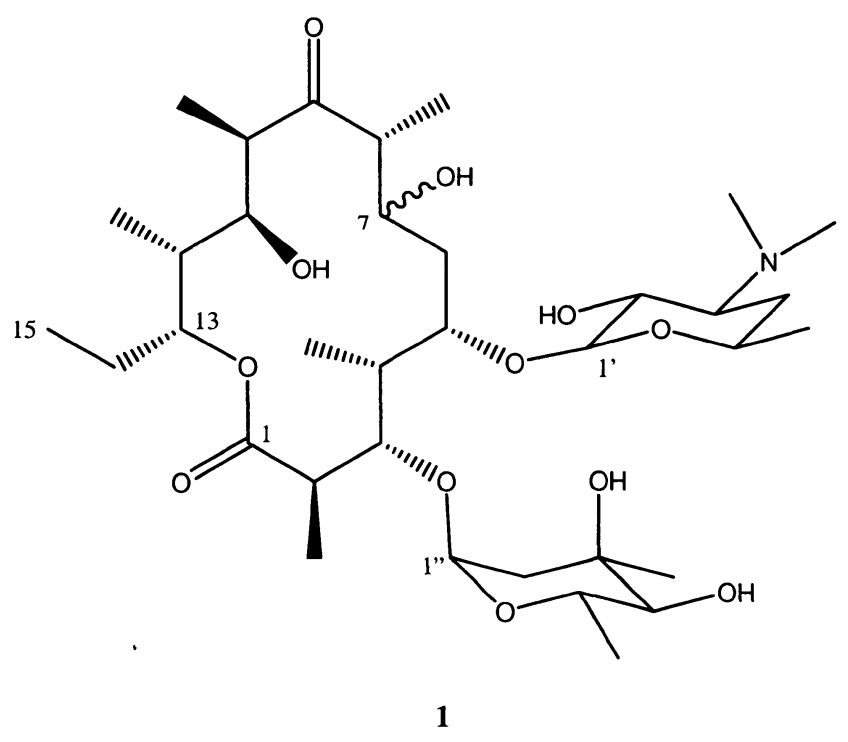

Table 2. Antibacterial activity of erythromycin A and 7-hydroxy-6-demethyl-6-deoxy erythromycin D.

\begin{tabular}{|l|c|c|}
\hline \multirow{2}{*}{ Microorganism } & \multicolumn{2}{c|}{ MIC $(\mu \mathrm{g} / \mathrm{ml})$} \\
\cline { 2 - 3 } & $\begin{array}{c}\text { Erythromycin } \\
\text { A }\end{array}$ & 1 \\
\hline S.pneumoniae & & \\
\hline ATCC6301 & 0.025 & 6.25 \\
\hline ATCC700671 & 0.049 & 12.5 \\
\hline ATCC700676 & 6.25 & 12.5 \\
\hline ATCC700677 & 6.25 & 6.25 \\
\hline ATCC700905 & 3.12 & 12.5 \\
\hline ATCC700906 & $>12.5$ & $>12.5$ \\
\hline ATCC49619 & 0.049 & 6.25 \\
\hline S. aureus & & \\
\hline ATCC6538p & 0.098 & $>12.5$ \\
\hline ATCC33591 & $>12.5$ & $>12.5$ \\
\hline ATCC14154 & $>12.5$ & $>12.5$ \\
\hline ATCCBAA-39 & $>12.5$ & $>12.5$ \\
\hline ATCCBAA-44 & $>12.5$ & $>12.5$ \\
\hline ATCC29213 & 0.20 & $>12.5$ \\
\hline S. epidermis & & \\
\hline ATCC12228 & 0.20 & $>12.5$ \\
\hline E. faecalis & & $>12.5$ \\
\hline ATCC51575 & $>12.5$ & $>12.5$ \\
\hline Haemophilus Influenzae & & \\
\hline ATCC9006 & 1.56 & \\
\hline ATCC49766 & 6.25 & $>12.5$ \\
\hline
\end{tabular}

erythonolide B is the first step in the pathway to convert 6$\mathrm{dEB}$ into erythromycins and is catalyzed by the cytochrome P450 oxidase EryF. ${ }^{8)}$ The unexpected hydroxylation of 
compound 1 at carbon C-7 rather than at C-6 presumably occurs due to an altered binding configuration of the substrate, 6-nor-erythronolide $B$, in the active site of the EryF oxidase. PETKOvic et al. ${ }^{9)}$ recently reported the production of 6-demethyl erythromycin $\mathrm{D}$, possessing the natural C-6 hydroxyl function, from a different engineered strain of $S$. erythraea. Although the alterations to the PKS (DEBS) genes are different from those reported here, this should not affect the specificity of EryF.

\section{Experimental Section}

\section{General Experimental Procedures}

HRESIMS were obtained by manual peak matching versus internal standards by high-resolution mass spectrometry using an Applied Biosystems Mariner TOF spectrometer configured with a Turbo-Ionspray source in positive ion mode. ${ }^{1} \mathrm{H}$ NMR $(400 \mathrm{MHz})$ and ${ }^{13} \mathrm{C}$ NMR $(100 \mathrm{MHz})$ were recorded with a Bruker DRX 400 spectrometer equipped with a Nalorac 3-mm MDG-400B probehead. Chemical shifts were referenced to $\delta 7.26$ and 77.0 for ${ }^{1} \mathrm{H}$ and ${ }^{13} \mathrm{C}$ NMR spectra, respectively. For each compound, ${ }^{1} \mathrm{H},{ }^{13} \mathrm{C}$, COSY, HMBC, and multiplicity-edited HSQC experiments were carried out.

\section{Strain and Expression Vector}

S. erythraea K24-1 was described previously. ${ }^{7)}$ The AT4modified DEBS gene, which has the two AT4 amino acids adjacent to His-201 mutated (mutation 3 in reference 6), was introduced into $S$. erythraea K24-1 by conjugation as described previously. ${ }^{7)}$ Briefly, the engineered PKS genes were transferred from the $S$. lividans expression vector to the pSET152 integrating vector under control of the ery $A p$ promoter by conventional cloning procedures resulting in the vector pKOS159-42, which was introduced into $S$. erythraea K24-1 by conjugation. Rapamycin-resistant transconjugants were confirmed to produce compounds with antibacterial activity against $M$. luteus using an agar plate bioassay.

\section{Media}

S. erythraea K24-1::pKOS159-42 was cultivated in seed (SE-V1) and production (SE-0.5F1) media. SE-V1 contained corn starch $16 \mathrm{~g}$, corn dextrin $10 \mathrm{~g}$, soy meal flour $15 \mathrm{~g}$, sodium chloride $2.5 \mathrm{~g}$, corn steep liquor $5 \mathrm{~g}$, ammonium sulfate $1 \mathrm{~g}$, soy bean oil $6 \mathrm{~g}$, and calcium carbonate $4 \mathrm{~g}$ in 1 liter of deionized water. SE-0.5F1 contained corn starch $17.5 \mathrm{~g}$, corn dextrin $16 \mathrm{~g}$, soy meal flour $16.5 \mathrm{~g}$, sodium chloride $3.5 \mathrm{~g}$, corn steep liquor $6 \mathrm{~g}$, ammonium sulfate $1 \mathrm{~g}$, soy bean oil $3 \mathrm{~g}$, and calcium carbonate $4 \mathrm{~g}$ in 1 liter of deionized water. The media were prepared by adding all components to $90 \%$ final volume with mixing. Then, the media were brought to final volume and autoclaved at $121^{\circ} \mathrm{C}$ for 90 minutes. After sterilization SE-0.5F1 was transferred to a sterile fermenter and adjusted to $\mathrm{pH} 7.0$ for fermentation. All media were supplemented with $1 \mathrm{ml} /$ liter Antifoam B (JT Baker) unless otherwise noted to prevent excessive foaming. SE-V1 was supplemented with $30 \mathrm{mg} /$ liter apramycin sulfate.

\section{Culture Conditions}

S. erythraea K24-1::pKOS159-42 was maintained as a cell bank consisting of $1 \mathrm{ml}$ vials frozen at $-80^{\circ} \mathrm{C}$ and was used to initiate the bioreactor seed train. A primary seed culture $\left(1^{\circ} \mathrm{S}\right)$ was started by inoculating $50 \mathrm{ml} \mathrm{SE}-\mathrm{V} 1$ (in $250 \mathrm{ml}$ flasks, Bellco \#2540) with 1 cell bank vial and was cultivated for 2 days at $34^{\circ} \mathrm{C}$ and $245 \mathrm{rpm}$ ( $1^{\prime \prime}$ orbital shaker). A secondary seed culture $\left(2^{\circ} \mathrm{S}\right)$ was prepared by transferring $50 \mathrm{ml}$ of $1^{\circ} \mathrm{S}$ to $500 \mathrm{ml} \mathrm{SE-V1}$ (in 2.8-liter Fernbach flasks, Bellco \#2554) and cultivating for 2 days at $34^{\circ} \mathrm{C}$ and $245 \mathrm{rpm}$. Finally, a Biostat CT (B. Braun) 10-liter fermenter containing 9 liters of SE-0.5F1 was inoculated with the secondary seed culture. The production fermenter was operated at $34^{\circ} \mathrm{C}, \mathrm{pH} 7.0 \pm 0.15,3 \mathrm{LPM}$ airflow, and $600 \mathrm{rpm}$ agitation. The $\mathrm{pH}$ was automatically controlled with $2.5 \mathrm{~N}$ sodium hydroxide or $2.5 \mathrm{~N}$ sulfuric acid. The dissolved oxygen was maintained above $40 \%$ of air saturation by manual control of airflow (3 5 LPM) and agitation $(600 \sim 750 \mathrm{rpm})$. Foaming was controlled by automatic addition of Antifoam B. At 24 hours after inoculation, a dextrin feed was started. The dextrin feed was prepared as a $150 \mathrm{~g} /$ liter dextrin suspension (requires mixing) and was fed at a rate of $5.4 \mathrm{ml} /$ hour. The feed was maintained until harvest on day 6 after inoculation.

$\begin{array}{lll}\text { Isolation } & \text { of } & \text { 7-Hydroxy-6-demethyl-6-deoxy } \\ \text { Erythromycin D }\end{array}$

Whole broth from two 10-liter fermentations of $S$. erythrea K24-1::pKOS159-42 was adjusted to $\mathrm{pH} 8$ and clarified by centrifugation. Erythromycins were captured by passing the supernatant over a column of HP20 sorbent (Mitsubishi), washing with water, and eluting with methanol. The resulting solid-phase extraction product was chromatographed on Diaion HP-20SS sorbent (Supelco) using a stepped gradient of $50 \sim 100 \% \mathrm{MeOH}$. LC/MS analysis of several later-eluting fractions indicated compounds having masses consistent with 6-demethylerythromycin D. These fractions were pooled and further fractionated by two rounds of isocratic $\mathrm{C}_{18}$ chromatography 
(Bakerbond, $40 \mu \mathrm{m}$ ), first in $67 \% \mathrm{MeOH} / 5 \mathrm{mM} \mathrm{NH}_{4} \mathrm{OAc}$, and then in $63 \% \mathrm{MeOH} / 5 \mathrm{mM} \mathrm{NH} \mathrm{NH}_{4} \mathrm{OAc}$, giving pools enriched in 1. Compound $\mathbf{1}$ was further purified by partitioning between ethyl acetate and saturated aqueous sodium bicarbonate, followed by $\mathrm{C}_{18}$ chromatography with a stepped gradient of $50 \sim 100 \% \mathrm{MeOH}$, to yield $10 \mathrm{mg}$.

Minimal inhibitory concentrations (MICs) of $\mathbf{1}$ against $S$. pneumoniae, $S$. aureus, $S$. epidermis, E. faecalis, and $H$. influenzae were determined using a microdilution technique (NCCLS document M7-A5). ${ }^{10)}$ Compounds were dissolved to $5 \mathrm{mg} / \mathrm{ml}$ in dimethylsulfoxide, diluted to $25 \mu \mathrm{g} / \mathrm{ml}$, and then further serially diluted 2-fold. An equal volume of cells $\left(\mathrm{A}_{600}=0.1\right)$ and drug dilution were mixed to give final drug concentrations between 0.006 and $12.5 \mu \mathrm{g} / \mathrm{ml}$. Cultures were grown overnight at $35^{\circ} \mathrm{C}$ in 96 -well plates, and MIC values were determined by visual inspection.

7-Hydroxy-6-demethyl-6-deoxy Erythromycin D (1): Yellow solid; $10 \mathrm{mg}$; UV (DAD, 50\% $\mathrm{MeCN}$ ) end absorption; IR (film) $v_{\max } 3509,2974,2938,1738,1711$, $1456,1373,1243,1182,1115,1050,1005 \mathrm{~cm}^{-1}$.

\section{Acknowledgment}

We thank N. VISWANATHAN for measuring mass spectra and WEI MA for the MIC assays.

\section{References}

1) Cortes, J.; S. F. Haydock, G. A. Roberts, D. J. Bevitt \& P. F. LEADLAY: An unusually large multifunctional polypeptide in the erythromycin-producing polyketide synthase of Saccharopolyspora erythraea. Nature 348: 176 178, 1990

2) Donadio, S.; M. J. Staver, J. B. Mcalpine, S. J.
SWANSON \& L. KATZ: Modular organization of genes required for complex polyketide biosynthesis. Science 252: 675 679, 1991

3) KATZ, L.: Manipulation of modular polyketide synthases. Chem. Rev. 97: 2557 2576, 1997

4) Rodriguez, E. \& R. MCDAniEl: Combinatorial biosynthesis of antimicrobials and other natural products. Curr. Opin. Microbiol. 4: 526 534, 2001

5) McDaniel, R.; A. Thamchaipenet, C. Gustafsson, H. Fu, M. Betlach, M. Betlach \& G. Ashley: Multiple genetic modifications of the erythromycin polyketide synthase to produce a library of novel "unnatural" natural products. Proc. Natl. Acad. Sci. 96: 1846 1851, 1999

6) Reeves, C.; S. Murli, G. Ashley, M. Piagentini, C. HUTCHINSON \& R. MCDANIEL: Alteration of the substrate specificity of a modular polyketide synthase acyltransferase domain through site-specific mutations. Biochemistry 40: 15464 15470, 2001

7) Rodriguez, E.; Z. Hu, S. Ou, Volchegursky, C. Hutchinson \& R. MCDANiEl: Rapid engineering of polyketide overproduction by gene transfer to industrially optimized strains. J. Ind. Microbiol. Biotechnol. 30: 480 488, 2003

8) Andersen, J. \& C. Hutchinson: Characterization of Saccharopolyspora erythraea cytochrome P450 genes and enzymes, including 6-deoxyerythronolide B hydroxylase. J. Bact. 174: 725 735, 1992

9) Petkovic, H.; R. Lill, R. Sheridan, B. Wilkinson, E. McCormick, H. McArthur, J. Staunton, P. Leadlay \& S. KENDREW: A novel erythromycin, 6-demethyl erythromycin D, made by substituting an acyltransferase domain of the erythromycin polyketide synthase. J. Antibiotics 56: 543 551, 2003

10) NCCLS. Methods for Dilution Antimicrobial Susceptibility Tests for Bacteria That Grow Aerobically; Approved Standard-Fifth Edition. NCCLS document M7-A5 (ISBN 1-56238-394-9). NCCLS, 940 West Valley Road, Suite 1400, Wayne, Pennsylvania 190871898 USA 